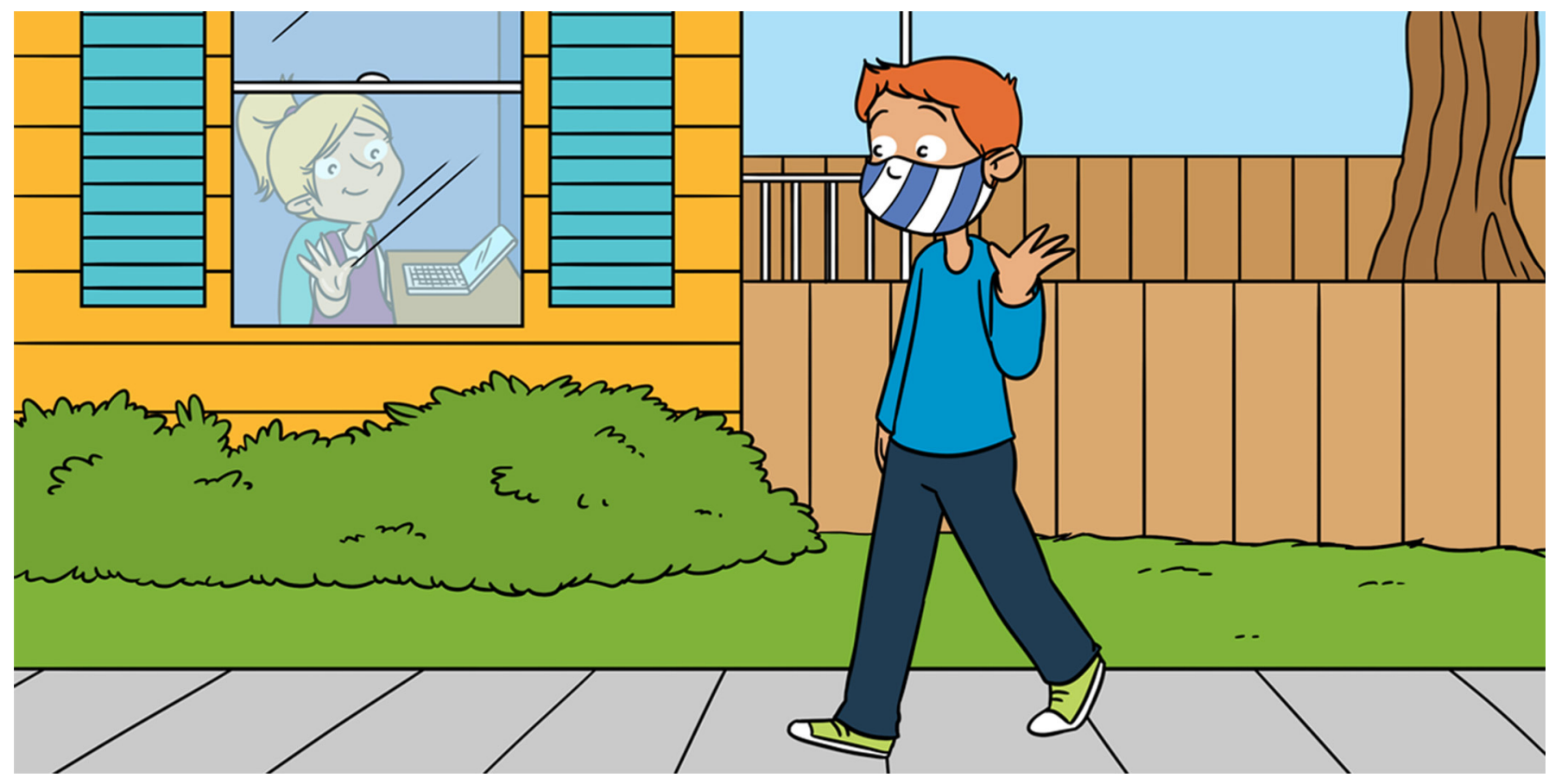

\title{
WHAT IS COVID-19?
}

\section{Gabriela Gama Freire Alberca, lara Grigoletto Fernandes, Maria Notomi Sato and Ricardo Wesley Alberca *}

Laboratory of Dermatology and Immunodeficiencies, LIM-56, Department of Dermatology, School of Medicine and Institute of Tropical Medicine of São Paulo, University of São Paulo, São Paulo, Brazil

\section{YOUNG REVIEWERS:}

MARINA

AGE: 14

MIRIAM

AGE: 14
COVID-19, the abbreviation for coronavirus disease 2019, is the name of the disease caused by a virus named SARS-CoV-2, an abbreviation for severe acute respiratory syndrome coronavirus 2 . The first report of this virus was in Wuhan, China, in November 2019 and now (Spring 2020) it has spread all over the world, so it is called a pandemic. This viral infection may cause fever, cough, tiredness, shortness of breath, and, in some cases, diarrhea. The infection usually causes mild symptoms in children and teenagers, but it can be lethal to the elderly. This virus can be spread between people very easily, so it is important to understand how to prevent its spread. The most effective ways to do this are by regularly washing hands with soap and water, maintaining a safe distance from other people, covering the mouth when coughing or sneezing, avoiding touching the face, eating a healthy diet, and staying home. 


\section{Figure 1}

What are the most common symptoms of COVID-19? The most common symptoms are fever, dry cough, sore throat, tiredness, aches and pains, and difficulty breathing.

\section{COVID-19}

(CORONAVIRUS

DISEASE 2019)

A disease caused by a virus called SARSCoV-2.

SARS-COV-2

(SEVERE ACUTE

RESPIRATORY

SYNDROME

CORONAVIRUS 2)

A newly discovered coronavirus that causes the disease

called COVID-19.

\section{PANDEMIC}

A disease that is spread all over the world.

\section{RESPIRATORY}

\section{SYSTEM}

A system responsible for breathing in oxygen and breathing out carbon dioxide. The primary organs of the respiratory system are the lungs, responsible for the exchange of gases as we breathe.

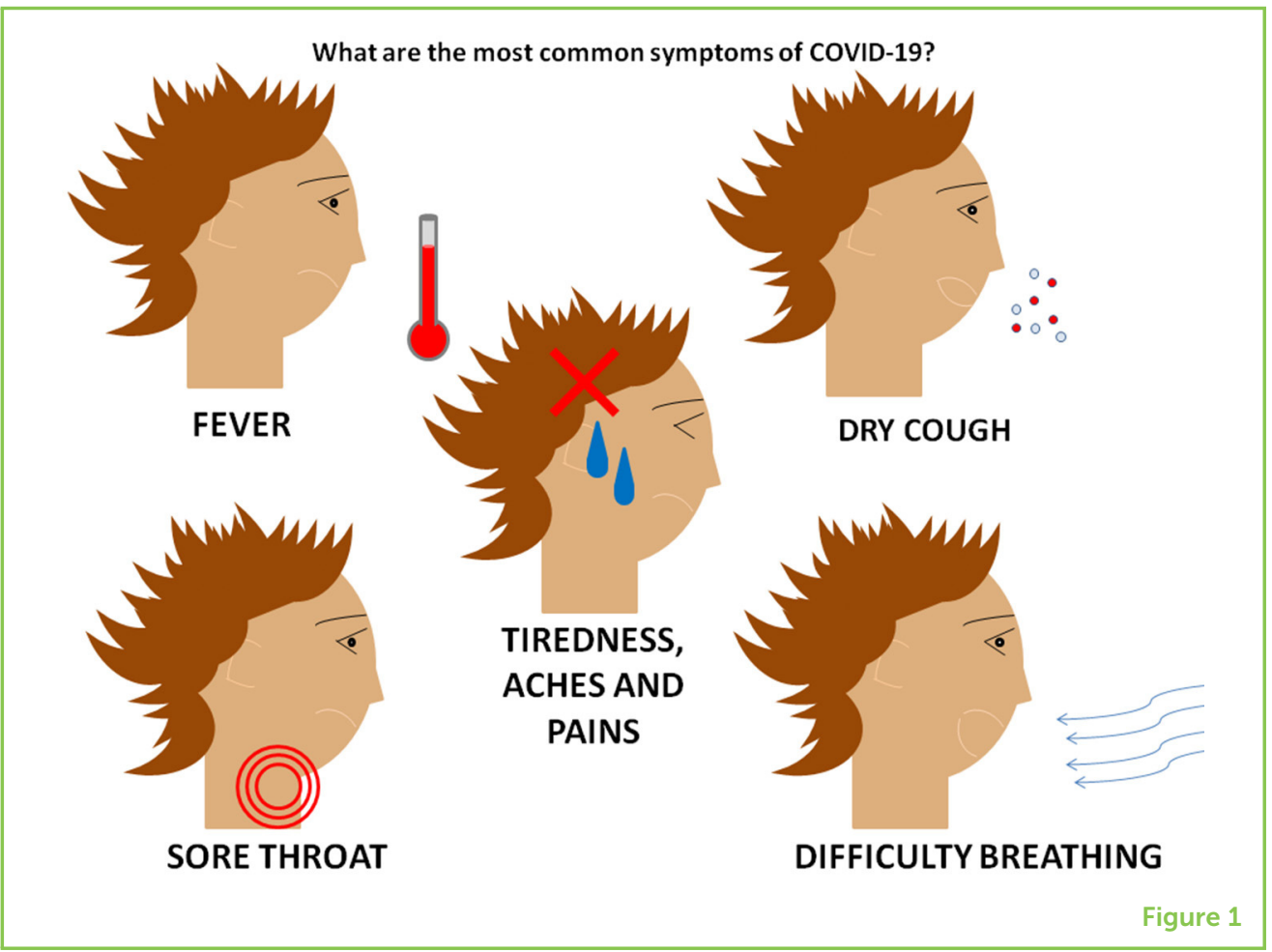

\section{WHAT IS COVID-19?}

COVID-19 is a new disease, caused by a type of virus named severe acute respiratory syndrome coronavirus-2 (SARS-CoV-2). It has now spread all over the world this is known as a pandemic. Coronaviruses are a family of viruses that can cause problems with the respiratory system. Previous infections by coronaviruses named SARS-CoV-1 (in 2002) and MERS-CoV (Middle East respiratory syndrome) (in 2012) have infected over 10,000 people.

The first report of SARS-CoV-2 was in November 2019, in Wuhan, China [1], but little is known about the exact origin. Currently, there is no specific treatment or vaccine for SARS-CoV-2. When someone is infected by this new virus, the person may or may not have any symptoms. If a person does have symptoms, those symptoms can range from mild to severe. The most common symptoms are fever, dry cough, tiredness, sore throat, and shortness of breath (Figure 1) [1]. These symptoms usually appear 2-14 days after the person is infected with the virus. It is estimated that every person infected will infect $\sim 2$ others. So, in this math problem, it is estimated that the number of infected people will double approximately every week during the initial outbreak.

\section{WHO IS AT RISK OF DEVELOPING A SEVERE FORM OF COVID-19?}

It is still not clear why some people develop severe symptoms and need intensive care and mechanical ventilation to help their lungs 


\section{Figure 2}

SARS-CoV-2 life cycle. (A) When SARS-CoV-2 gets into the body, it binds to the ACE-2 receptor on cells in the lungs. (B) The virus is then taken up by the cell. (C) Once inside, the virus releases its genetic material and hijacks the cell's replication machinery to produce new viruses. (D) The newly created SARS-CoV-2 are released from the cell to start the process over again.

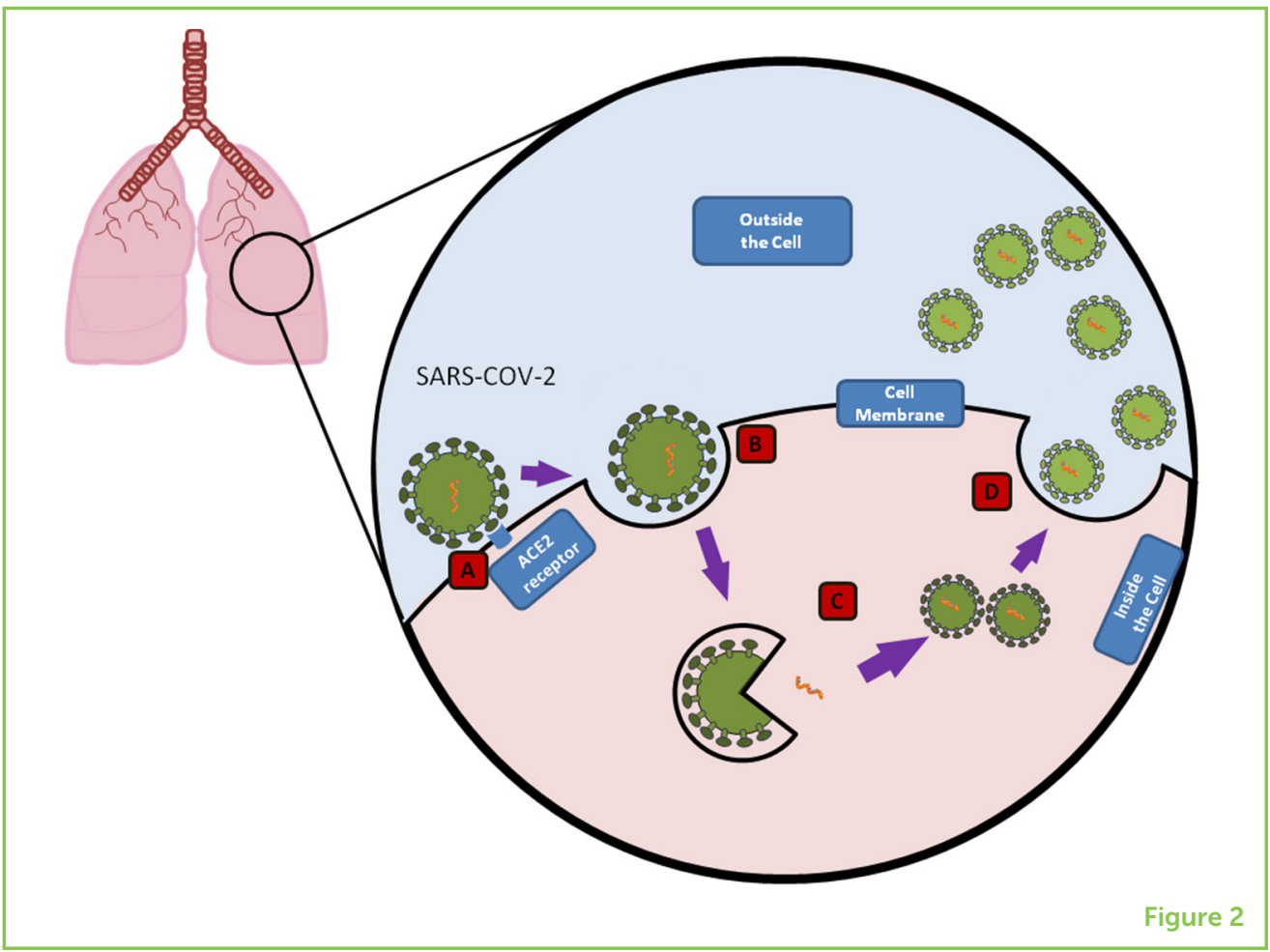

to function properly. It is known that people with some pre-existing conditions, such as diabetes and high blood pressure, as well as older people (people aged 60 years or older) have a higher risk of developing severe complications and being hospitalized. While children, teenagers, and young adults are not immune to SARS-CoV-2, they do not develop severe symptoms as often. Investigations are still ongoing to identify other possible factors that may cause people to have a severe form of COVID-19. Factors such as chronic respiratory disease and cancer [2] may play a role in the development of severe symptoms. It is also unclear if there are any long-term effects associated with COVID-19.

\section{HOW DO PEOPLE GET INFECTED?}

SARS-CoV-2 is a respiratory virus, so it is spread mainly from person to person when an infected person sneezes, coughs, or talks. Very small droplets of saliva can be expelled by an infected person during these actions, and the droplets can carry the virus into direct contact with another person's nose, eyes, or mouth.

Interestingly, the virus can still be found on materials like stainless steel or plastic, even several days after the material has become contaminated [3]. So, if you put your hand on a surface contaminated with SARS-CoV-2 and then touch your mouth, eye, or nose, you could possibly become infected. 


\section{ACE2 RECEPTOR}

The molecule on the cell surface that is used by SARS-CoV-2 to invade host cells.

\section{INFLAMMATION}

The protective reaction of the body against an infection or an injury, resulting in heat, redness, and swelling. If inflammation is not controlled, it can be harmful to the body.

\section{POLYMERASE}

CHAIN REACTION (PCR)

A method that enables us to make copies of the genetic material in a sample. Therefore, this method helps in a rapid detection if there is SARS-CoV-2 genetic material in the sample, even if the quantity is very small.

\section{ANTIBODY}

A protein produced by the immune system in response to a virus or other microorganism that helps to protect the body from reinfection with that same organism. Antibodies called IgM are produced early during infection and others called IgG are produced later.

\section{WHY DOES THE VIRUS ATTACK THE LUNGS?}

Even through SARS-CoV-2 can enter the body by many routes, it can only infect a cell if that cell has a molecule on its surface called ACE-2. This molecule is called the receptor (ACE2 receptor), and it is present in high amounts on the cells of the lungs. This is the reason SARS-CoV-2 primarily attacks the lungs and reproduces inside lung cells (Figure 2). As the virus enters the lungs, the infected person's immune system tries to eliminate the virus, generating a huge amount of inflammation in the lungs. The inflammation can end up damaging the tissues of the lungs, causing shortness of breath.

\section{HOW DO WE KNOW IF A PERSON HAS BEEN INFECTED?}

If a person has been experiencing the common symptoms of COVID-19 for more than a few days, a doctor may order a test to determine if the person has been infected with SARS-CoV-2. There are two ways to know if a person is infected or has been infected recently.

One test can determine whether the sick person currently has SARS-CoV-2 in his or her body. For this test, the medical team usually collects a sample of fluid from the nose with a swab. Since the quantity of virus collected this way is very small, a technique called polymerase chain reaction (PCR) is used to make lots of copies of the genetic material of the virus, so that lab workers will be able to see whether the virus is present in the sample (Figure 3A).

Another way to test if a person has been infected with SARS-CoV-2 is to analyze whether the person has antibodies to the virus. Antibodies are only created after a person has been exposed to a virus, and they help to protect the person from getting infected again. Depending on the type of antibodies, it is possible to know if the infection is recent (the test will show the presence of a type of antibody called $\lg M$ ) or if the person was infected in the past (the test will show the presence of another kind of antibody, called IgG) (Figures 3B-G) [4].

If a person is infected, it is very important for the person to isolate themselves and minimize contact with others, to avoid spreading the infection. The medical team that diagnoses the person will provide all the necessary information to help the sick person self-isolate effectively.

\section{HOW CAN WE PREVENT COVID-19?}

To protect ourselves and to protect others who may be more vulnerable to severe COVID-19, we can take some simple actions. According to the World Health Organization, it is essential to maintain 
Figure 3

How does a

coronavirus test work?

(A) How do we test for the virus?: A small sample of fluid is collected from the nose with a swab, and then the medical team looks for the genetic sequence of

SARS-COV-2 in the sample. (B) How do we test for antibodies?: A blood sample is collected and placed in the correct spot on the test kit, and the results will then appear in the window, showing 5 possible outcomes. (C) If the positive control does not light up, the test is not valid. (D) If the positive control light up, but there is no $\lg M$ or $\lg G$, the person does not have antibodies against SARS-CoV-2 and was therefore not infected. (E-G) If the positive control and IgM and/or IgG light up, the person has been infected and is producing antibodies against SARS-CoV-2.
A.

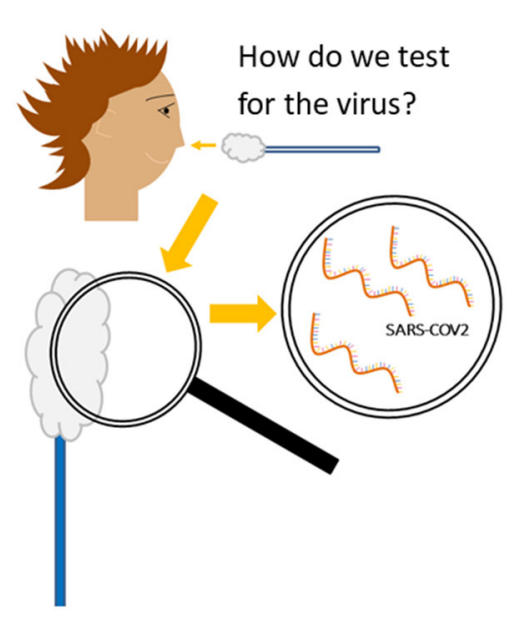

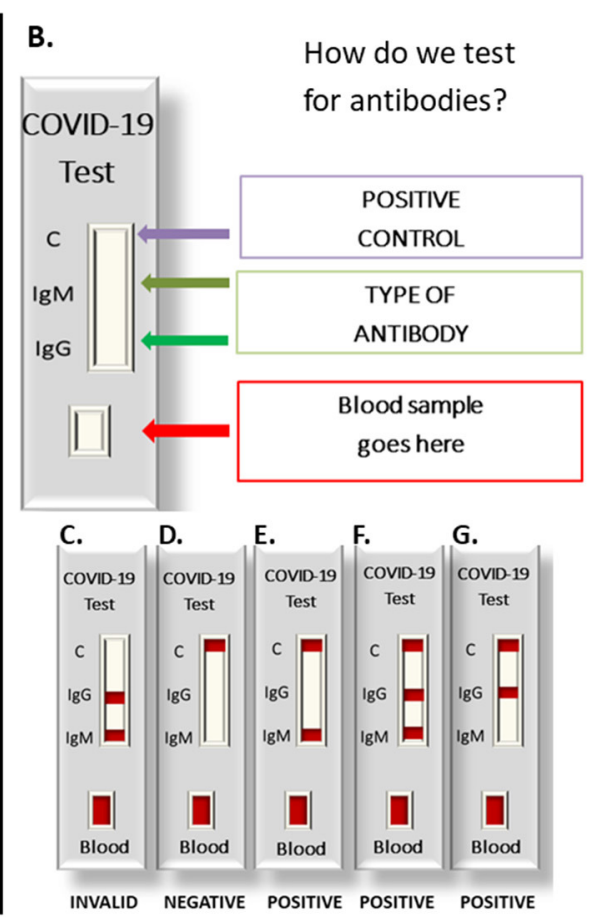

Figure 3

some distance (1-2 m) when talking to other people. We should also avoid crowded places, wash our hands with soap and water frequently or use hand sanitizers that contain $70 \%$ alcohol. It is also very important to avoid touching our faces and to cover our mouths with our arms when we cough or sneeze. We may also be asked to wear face masks in public places (Figure 4) [5]. These procedures can help reduce the spread of the virus and help us make sure that hospitals do not get overcrowded, so that everyone who needs medical help can get it.

All over the world, different treatments are being tested in individuals infected with SARS-CoV-2, but it will take some time to identify which drugs are effective and safe. Many drugs aim to prevent the virus from infecting other cells or from replicating to produce more viruses. Vaccines are also being developed. Vaccines are given to people before they get sick, to prevent the disease from happening. It is important to remember that safe and effective vaccines can take a long time to develop. Because many scientists and doctors around the world are working hard to help people with SARS-CoV-2, it is possible that treatments and a vaccine may emerge within the near future.

\section{SUMMARY}

In conclusion, SARS-COV-2 is a new coronavirus that can cause a severe disease named COVID-19. There is currently no specific treatment or vaccine available for this virus. Although some people 
Figure 4

How to prevent SARS-CoV-2 infection. (A) Maintain some distance (1-2 $\mathrm{m}$ ) when talking to other people. (B) Stay at home or avoid crowded places. (C) Wash hands with soap and water frequently, or use alcohol-based hand sanitizers. (D) Cover your mouth with your arm when you cough or sneeze. (E) Avoid touching your face. (F) Wear a protective mask.

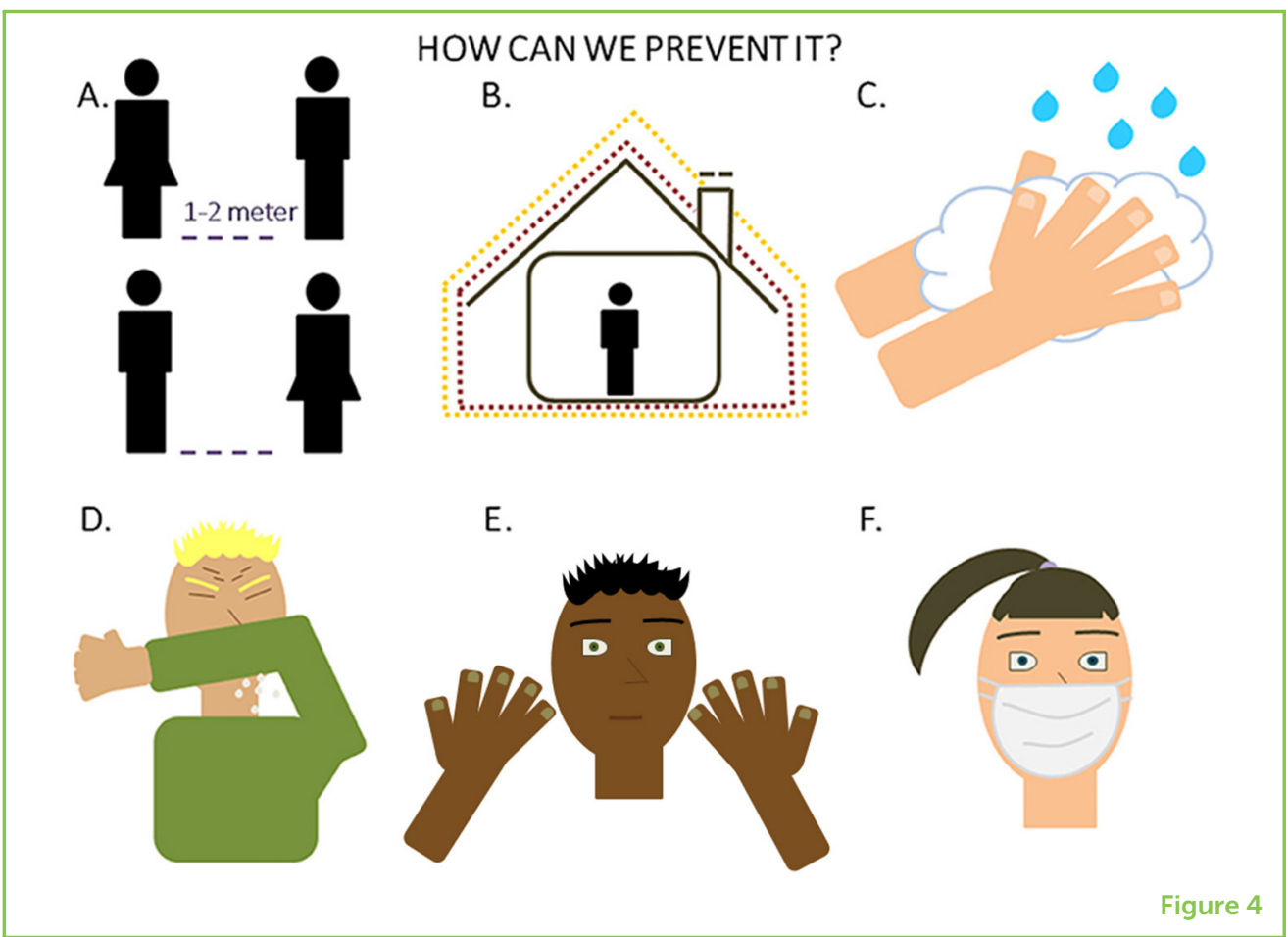

may not have symptoms, they may still be infected and able to infect other people, some of whom may go on to develop severe COVID-19. To protect ourselves and others, many actions can be of great value, such as maintaining distance between yourself and others, avoiding crowded places, washing your hands frequently with soap and water, and covering your mouth when you cough or sneeze. These simple steps will help people all over the world to stay safe from COVID-19.

\section{AUTHOR CONTRIBUTIONS}

GA contributed to the conception, drafting, and review of the manuscript. IF contributed to review and illustration. MS contributed to review. RA contributed to the conception, illustration, drafting, and review of the manuscript.

\section{REFERENCES}

1. Huang, C., Wang, Y., Li, X., Ren, L., Zhao, J., Hu, Y., et al. 2020. Clinical features of patients infected with 2019 novel coronavirus in Wuhan, China. Lancet. 395:497-506. doi: 10.1016/S0140-6736(20)30183-5

2. Yu, N., Li, W., Kang, Q., Xiong, Z., Wang, S., Lin, X., et al. 2020. Clinical features and obstetric and neonatal outcomes of pregnant patients with COVID-19 in Wuhan, China : a retrospective, single-centre, descriptive study. Lancet Infect Dis. 20:559-64. doi: 10.1016/S1473-3099(20)30176-6

3. Chin, A. W. H., Chu, J. T. S., Perera, M. R. A., Hui, K. P. Y., Yen, H.-L, Chan, M. C. W., et al. 2020. Stability of in different environmental conditions. Lancet Microbe. 1:E10. doi: 10.1016/S2666-5247(20)30003-3 
4. Li, B., Feng, F., Yang, G., Liu, A., Yang, N., Jiang, Q., et al. 2020. Immunoglobulin $\mathrm{G} / \mathrm{M}$ and cytokines detections in continuous sera from patients with novel coronaviruses (2019-nCoV) infection. SSRN Electron J. doi: 10.2139/ssrn. 3543609

5. World Health Organization (WHO). 2020. Rational Use of Personal Protective Equipment for Coronavirus Disease 2019 (COVID-19). WHO.

SUBMITTED: 18 April 2020; ACCEPTED: 15 May 2020; PUBLISHED ONLINE: 20 May 2020.

EDITED BY: Jorge Galindo-Villegas, Nord University, Norway

CITATION: Alberca GGF, Fernandes IG, Sato MN and Alberca RW (2020) What Is COVID-19? Front. Young Minds 8:74. doi: 10.3389/frym.2020.00074

CONFLICT OF INTEREST: The authors declare that the research was conducted in the absence of any commercial or financial relationships that could be construed as a potential conflict of interest.

COPYRIGHT @ 2020 Alberca, Fernandes, Sato and Alberca. This is an open-access article distributed under the terms of the Creative Commons Attribution License (CC BY). The use, distribution or reproduction in other forums is permitted, provided the original author(s) and the copyright owner(s) are credited and that the original publication in this journal is cited, in accordance with accepted academic practice. No use, distribution or reproduction is permitted which does not comply with these terms.

\section{YOUNG REVIEWERS}

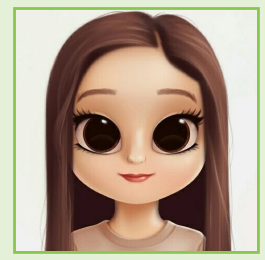

\section{MARINA, AGE: 14}

I decided to review this article because I think it is a really serious problem, since currently there is no vaccine against coronavirus. I think it is really important, not only for people my age, but for everyone, to know as much as possible about the coronavirus. Because if we all collaborate, we can stop this as soon as possible. I highly recommend reading these types of articles and staying safe from this misfortune.

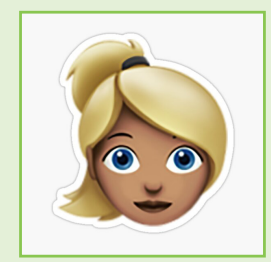

\section{MIRIAM, AGE: 14}

I really like science and I was curious to learn more about COVID-19. I wanted to help improve this article by giving my opinion because this virus is a huge problem now, and we have never seen something similar to this worldwide pandemic. I watch and listen to the news a lot these days and reading this article gave me the feeling I understand what is happening.

\section{AUTHORS}

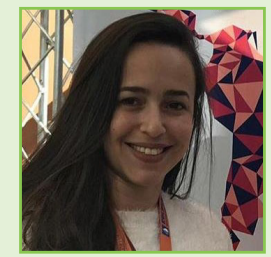

\section{GABRIELA GAMA FREIRE ALBERCA}

I am a Ph.D. student at the Institute of Biomedical Science at the University of São Paulo. My research focuses on understanding the influence of gastrointestinal bacteria on the development of diseases. In my free time, I enjoy cooking. 

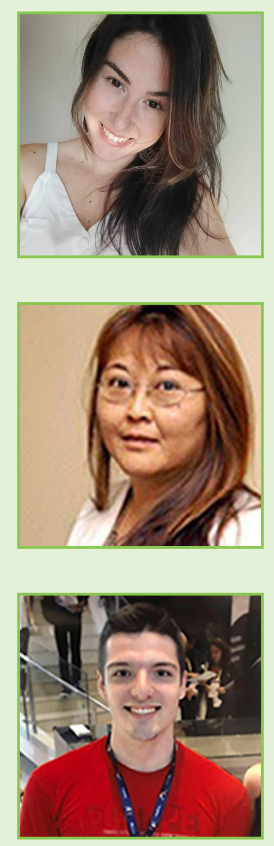

\section{RICARDO WESLEY ALBERCA}

I am a post-doctoral researcher at the University of Sao Paulo. My research focuses on the development of treatments for respiratory diseases, like asthma and other inflammatory syndromes. I enjoy books and movies. *ricardowesley@usp.br 